\title{
Cancer pain - come so far, but so far to go!
}

\author{
Robin L Fainsinger MD
}

$\mathrm{T}$ he lines from a number of songs come to mind as I contemplate the international progress and issues contained in this special issue, dedicated to the International Association for the Study of Pain 2009 global focus on cancer pain. We have come a long way in many countries, but much of the world's population has been left behind. Following this editorial, we are pleased to publish brief articles summarizing issues and progress in cancer care in 14 countries and regions around the globe. We are grateful to the authors for providing their perspective.

Canadians should feel relieved and proud - our status as a world leader in cancer pain opioid consumption provides more assurance of access to necessary cancer pain treatment than the citizens of most other countries can expect. Opioids are widely available in Canada (similar to most developed countries) and include morphine, hydromorphone, oxycodone, fentanyl and methadone. Canada leads the world in global per capita consumption of hydromorphone (17 mg per capita) and is second for oxycodone (108 mg per capita) and morphine (62 mg per capita) (1). Reports from Canada, Europe, the United Kingdom, the United States, Ireland, Australia, New Zealand and Israel document significant advances in basic pain research, leadership and innovation in the development of regional programs, development and use of assessment tools (2), educational initiatives and research infrastructure (3).

The optimistic view of developed countries is tempered by the caution expressed in the Irish report, in which significant academic and clinical gaps still exist, including the failure to generate quality audit data, health care professionals' knowledge deficits regarding cancer pain, lack of collaborative engagement in research studies, and inequitable development of specialist cancer pain management services, most notably palliative care. These gaps exist to varying degrees in all countries and the projected demographic changes warning of an increase in the number of cancer pain patients should encourage us all to continue to advocate for more progress.
Moving to the Far East, the reports from Japan and Singapore document impressive recent progress, although the measure of opioid consumption lags behind the world average. Some opioids, such as methadone and hydromorphone, are not available or are limited to oral use. In Thailand, progress is limited by the undermet need for education of health care professionals, a restrictive national drug policy and negative public attitudes toward opioids. As a result, opioid consumption is even lower than in Japan and Singapore.

The news from Argentina documents many problems, despite some progress. Availability of care, despite some team development, is poor; bureaucracy at the public service level and lack of a public health strategy for cancer pain and palliative care limit progress. An ambitious and innovative approach of educating the public to produce pressure for social change has been proposed as a solution. In 2006, morphine and methadone consumption was $0.66 \mathrm{mg}$ and $0.24 \mathrm{mg}$ per capita, respectively; as a comparison, global mean consumption for the same period was $5.98 \mathrm{mg}$ and $8.74 \mathrm{mg}$ per capita, respectively (4).

The per capita morphine consumption in Saudi Arabia is less than $0.35 \mathrm{mg}$, which is alarmingly low compared with the global mean. This is obviously not a financial issue as it would be for many countries in Africa. There are inevitably multiple factors contributing to the potential obstacles hindering cancer pain control. However, factors related to health professionals' knowledge and practice, and the need to invest more in palliative care training once again seem to play a major role. This suggests a strong role for countries such as Canada, with well-developed educational programs, to continue to assist as we have with training fellows from Saudi Arabia alongside residents in our own accredited residency training programs.

The mean consumption of morphine for the African region is the lowest of all the World Health Organization regions of the world, at $0.7 \mathrm{mg}$ per capita. It is somewhat gratifying as an immigrant from South Africa (where I received my undergraduate 
medical training) to see that country ranked highest in the region, with morphine consumption at $1.92 \mathrm{mg}$ per capita (2). However, the contrast with the Canadian figure of $62 \mathrm{mg}$ per capita and consideration of the implication for cancer pain management is depressing. For much of Africa where opioids are available, cost is a major constraint for many. This, coupled with lack of knowledge and inadequate training for health care professionals, inevitably presents a formidable challenge for patients seeking access to adequate cancer pain management.

Despite the perceived hard economic times, uncertainty, pressures and changes in the Canadian health care system, we can take pride in our progress in the arena of cancer pain management. At the same time, we need to continue to ensure we maintain this momentum and strive to do better while considering our obligations to help much of the rest of the world, who could benefit from our clinical and educational expertise, and advocacy and financial support. How we can accomplish this as organizations and individuals is a challenge we need to accept - a pity this is not as simple as following the yellow brick road.

\section{REFERENCES}

1. Canada. <http://www.painpolicy.wisc.edu/ internat/AMRO/Canada/index.htm > (Current at September 30, 2009).

2. Hjermstad MJ, Fainsinger RL, Kaasa S. Assessment and classification of cancer pain. Curr Opin Support Palliat Care 2009;3:24-30.

3. Fainsinger RL. Global warming in the palliative care research environment Adapting to change. Palliat Med 2008;22:328-35.

4. Country profiles. $<$ http://www.painpolicy.wisc. edu/internat/countryprofiles.htm $>$ (Current at September 30, 2009). 


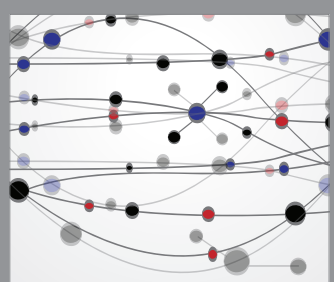

The Scientific World Journal
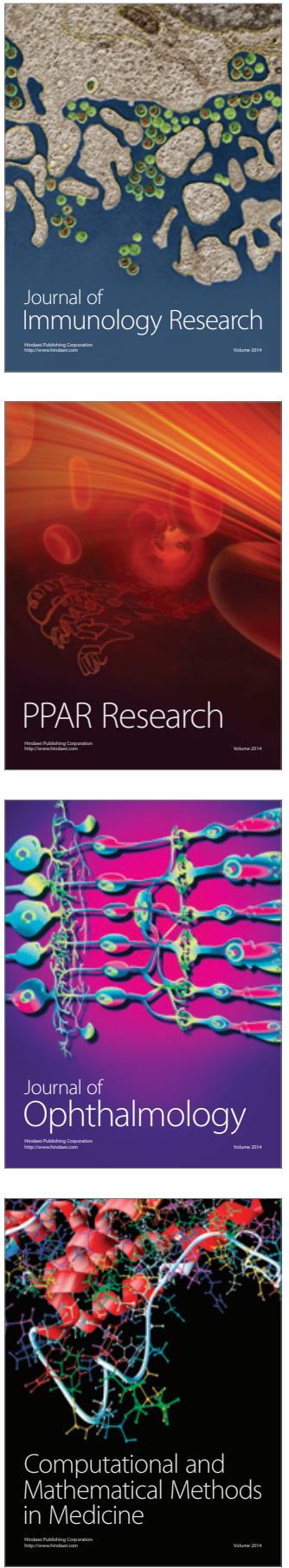



Gastroenterology Research and Practice



\section{Hindawi}

Submit your manuscripts at

http://www.hindawi.com
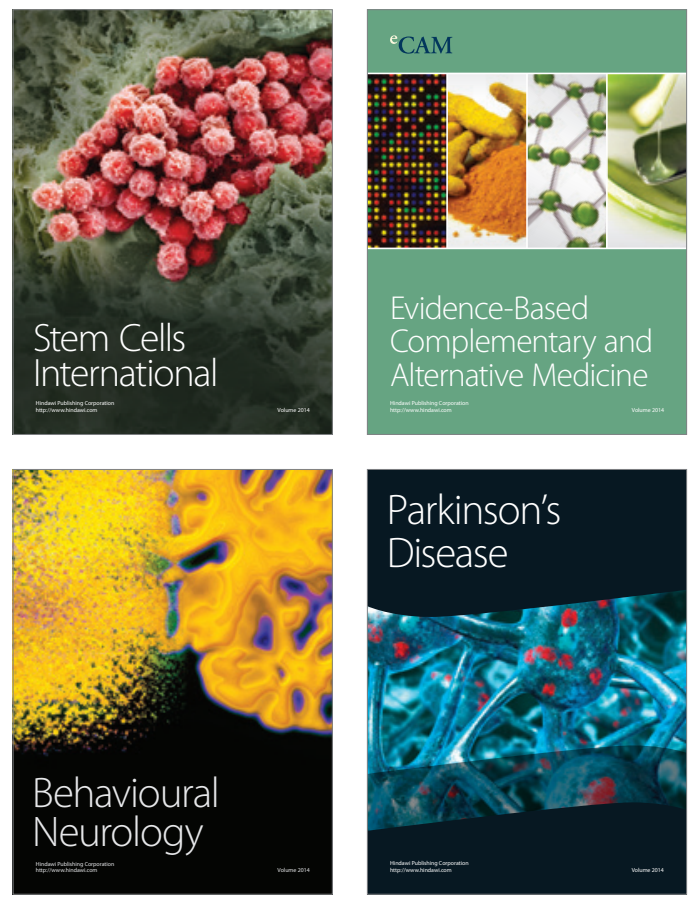
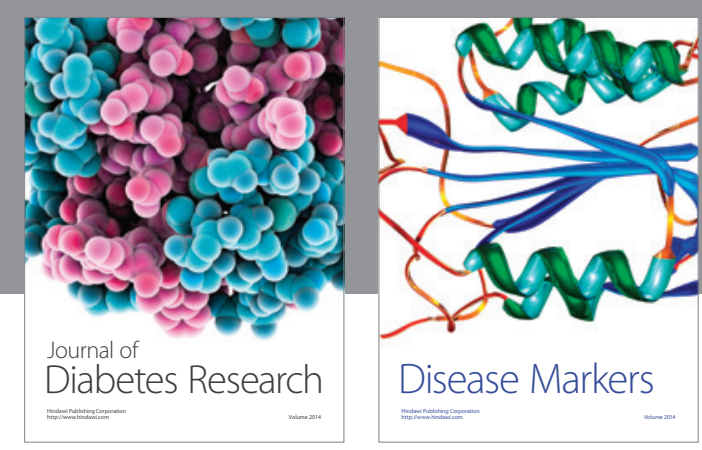

Disease Markers
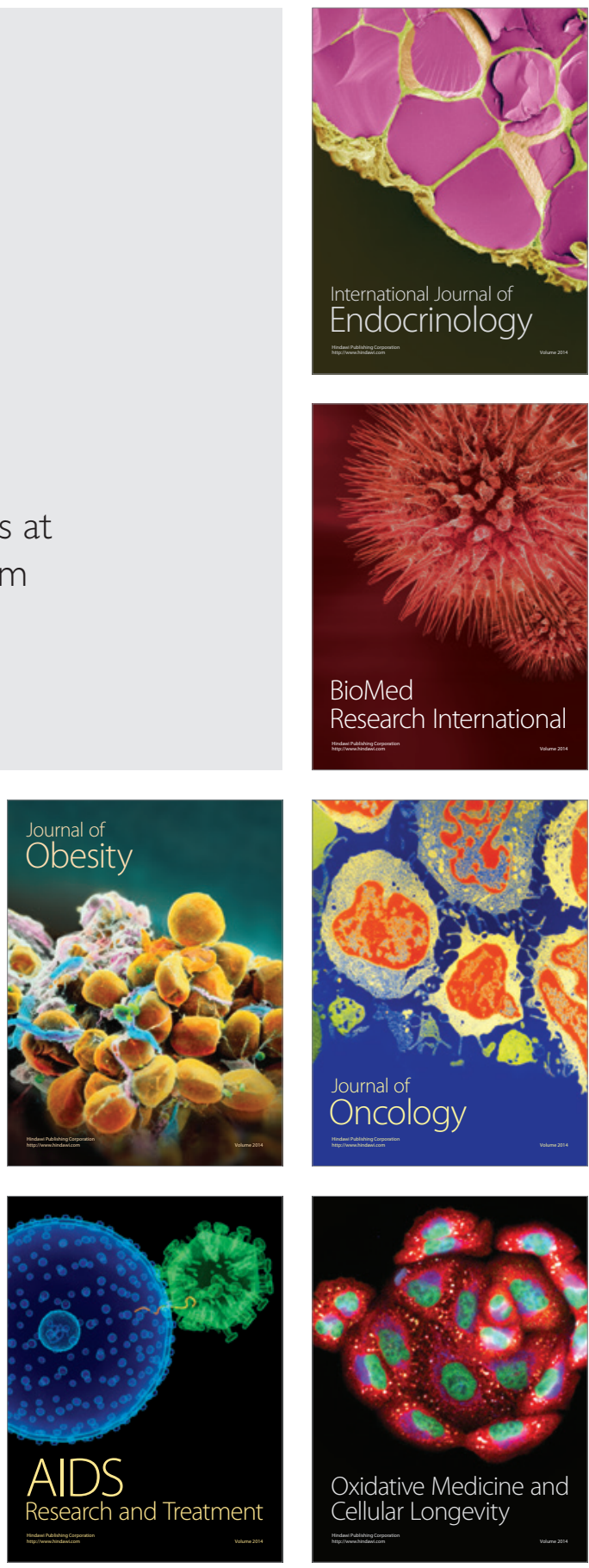